\title{
Obesidade mórbida: quando comer vai muito além do alimento
}

Morbid obesity: when eating goes way beyond food

Obesidad mórbida: cuando el comer va mucho más allá del alimento

\author{
Livia Janine L. F. Rocha* \\ Junia de Vilhena ${ }^{* *}$ \\ Joana de Vilhena Novaes ${ }^{* * *}$
}

\begin{abstract}
Resumo
Com a premissa psicanalítica de que o sujeito se constitui pelo Outro, em uma sociedade em que o mote é a ação e o prazer, buscamos pensar o laço do obeso mórbido com a comida. Uma vez que se objetivou abrir questôes em vez de dar respostas conclusivas, não deixamos de pensar: como ele se relaciona com seu desejo e com a falta intrínseca a todo sujeito? Como se articula o modo de gozar que o caracteriza? Como lida com seu corpo? É preciso que esse modo de gozar seja modificado? Abordamos, também, a busca pela cirurgia bariátrica, recurso cada vez mais utilizado. Contudo, é preciso não se buscar soluções ou respostas fora do sujeito, sem acesso às questôes subjetivas envolvidas na obesidade mórbida e na busca pela cirurgia. A obesidade é paradigmática em uma sociedade onde uma das formas de padecer é a compulsão, enquanto a tecnologia permite novas ações sobre o corpo antes impossíveis.
\end{abstract}

Palavras-chave: obesidade mórbida; psicanálise; cultura; cirurgia bariátrica; corpo.

\section{Abstract}

Considering the psychoanalytic premise that the subject constitutes himself through the Other, in a society based on performance and pleasure, we discuss the bond between morbid obesity and food. As we intend to invite questions instead of providing conclusive answers, we

\footnotetext{
Texto recebido em dezembro de 2008 e aprovado para publicação em julho de 2009.

Doutora do Programa de Pós-graduação em Psicologia Clínica da PUC Rio, psicóloga, e-mail: liviajrocha@gmail.com.

** Doutora em Psicologia Clínica e psicanalista, professora do Programa de Pós-graduação em Psicologia Clínica da Pontifícia Universidade Católica do Rio de Janeiro - PUC RJ, e-mail: vilhena@puc-rio.br.

*** Pós-doutora em Psicologia Social pela UERJ, doutora em Psicologia Clínica pela PUC Rio, pós-doutoranda em Clínica Médica pela UERJ, coordenadora do Núcleo de Doenças da Beleza da PUC Rio, psicanalista, pesquisadora do Laboratório de Pesquisas Clínica e Experimental em Biologia Vascular (Bio-Vasc) da UERJ, pesquisadora e psicoterapeuta do LIPIS, pesquisadora correspondente do Centre de Recherches Psychanalyse et Médecine -Université Denis-Diderot Paris 7 CRPM-Pandora - PUC RJ, e-mail: joananovaes@terra.com.br.
} 
also discuss issues such as: How does this individual relate himself with his desire and with the subject's intrinsic lack? How is the juissance that characterizes him articulated? How does he deal with his body? Is it necessary to change this kind of juissance? We also discuss the increasing search for bariatric surgery nowadays. It is important, however, not to search for answers outside the subject, putting aside subjective questions involved in morbid obesity and the option for surgery. Obesity is paradigmatic in a society where one of the multiple ways of suffering is compulsion, while technology allows previously impossible body interventions.

Key words: Morbid obesity; Psychoanalysis; Culture; Bariatric surgery; Body.

\section{Resumen}

Teniendo en cuenta la premisa psicoanalítica que el individuo se constituye a partir del Otro, hablamos del vínculo entre la obesidad mórbida y la comida, en una sociedad basada en la acción y el placer. Como tenemos la intención de incitar a las preguntas en lugar de dar respuestas concluyentes, también examinamos: ¿cómo se relaciona este individuo con su propio deseo y la falta intrínseca que lo marca? ¿Cómo se articula la forma de gozar que lo caracteriza? ¿Cómo se ocupa de su cuerpo? ¿Es necesario cambiar esta forma de gozar? Abordamos, también, la búsqueda por la cirugía bariátrica, cada vez más utilizada hoy en día. Sin embargo, es necesario no buscar soluciones o respuestas fuera del sujeto, dejando de lado las cuestiones subjetivas relacionadas a la obesidad mórbida y a la opción de la cirugía. La obesidad es paradigmática en una sociedad donde una forma de sufrimiento es la compulsión, mientras la tecnología permite nuevas acciones en el cuerpo antes imposibles.

Palabras clave: obesidad mórbida; psicoanálisis; la cultura; la cirugía bariátrica; cuerpo

\section{Introdução}

\ obesidade mórbida é comumente identificada pelo grande acúmulo de gordura, e de acordo com a Organização Mundial de Saúde ${ }^{1}$, é diagnosticada especificamente pelo cálculo do "índice de massa corporal", padrão reconhecido internacionalmente cujo valor é o peso dividido pela altura ao quadrado: $\mathrm{kg} / \mathrm{m}^{2}$. Quando esse valor resulta entre 40 e 49,9, é diagnosticada a obesidade grau III, conhecida como obesidade mórbida, e quando dá igual ou acima de 50, a denominação é de superobeso.

\footnotetext{
${ }^{1}$ Para mais informações, remetemos o leitor ao site da Organização Mundial de Saúde (World Health Organization, 2009).
} 
As comorbidades são importantes no diagnóstico principalmente no caso da indicação para cirurgia bariátrica, pois, de acordo com a resolução do Conselho Federal de Medicina $\mathrm{n}^{\circ} 1.766 / 05^{2}$, pacientes com obesidade moderada (ou obesidade grau II, com IMC entre 35 e 39,9) só podem submeter-se a essa cirurgia se tiverem comorbidades associadas e que estejam ameaçando a vida. Algumas delas: problemas cardiovasculares, distúrbios menstruais, apneia do sono, doenças cerebrovasculares, osteoartrites, diabetes e hipertensão arterial. O nosso foco, aqui, são as pessoas com obesidade mórbida (grau III) e os superobesos.

Atualmente, a excessiva preocupação com a beleza, a saúde e o corpo, as inúmeras práticas de trabalho corporal, técnicas de intervenção, todo o mercado cosmético e de vitaminas, tudo isso denota a importância atual em cultivar a juventude, a beleza, o corpo saudável e a boa forma, é um estilo de viver, um estilo de ser. É nesse contexto que vemos a gordura adquirir status de doença.

A imagem do gordo não vem sem ambiguidades: de um lado, o Rei Momo, o gordinho simpático e amável; de outro lado, o gordo que inspira horror, ojeriza. Como sublinha Novaes (2007), a exclusão é tamanha, que essa verdadeira lipofobia acarreta uma espécie de morte social do gordo, seu afastamento severo dos espaços públicos. Além de doença, a obesidade mórbida é também uma categoria de exclusão social (Novaes, 2006). É o que encontramos com abundância nos depoimentos dos obesos. Mas o que nos mostra esse obeso que nos causa repulsa?

A tecnologia promete beleza, saúde, prazer e vitalidade, eliminando assim a inquietude que o olhar do outro provoca. Doravante cada um pode ser belo, sem celulites, sorriso e nariz perfeitos, corpo esculpido como desejado, nenhum defeito que não seja corrigido, nenhum detalhe que não seja alcançado. Os avanços tecnocientíficos e o desenvolvimento da nova medicina, observa Novaes (2003), colocaram em questão, desde a segunda metade do século $\mathrm{XX}$, aspectos da condição humana que pareciam intangíveis. Dessa forma, nota-se que os avanços científicos, tais como a biotecnologia, reproduzem valores que espelham o nosso imaginário cultural, em que as regulações sobre o corpo se fazem tão aparentes.

Entre o corpo e o olhar do outro nada de inquietação, só beleza a contemplar, desejo a satisfazer. Mas essa matemática não é tão simples (um "eu perfeito"

\footnotetext{
Para mais informaçôes, remetemos o leitor ao site do Conselho Federal de Medicina, no seguinte endereço: <http://www. portalmedico.org.br/resolucoes/cfm/2005/1766_2005.htm> e também para o site da Sociedade Brasileira de Cirurgia Bariátrica e Metabólica, no endereço: <http://www.sbcbm.org.br/materias. php?cod=19>.
} 
fazendo par com um "outro satisfeito"), e não é sem consequências exigir do homem que ultrapasse constantemente seus limites em busca de uma dita perfeição (Rocha, 2007).

É aí que a leitura da psicanálise pode contribuir, propondo, diante dessa obesidade que é doença, exclusão social e causadora de horror, uma leitura que remete menos a um estado doentio do que a um sujeito do inconsciente. Assim sendo, partimos aqui de uma premissa fundamental: o sujeito se constitui desde o Outro, é nessa via que buscamos abrir algumas questôes sobre esse laço mortífero com a comida. Para tanto, além de sujeito e Outro, recorremos a conceitos como alienação-separação, desejo, falta, gozo, compulsão à repetição.

O obeso mórbido pode beliscar o dia todo e fazer as refeições em família, comendo muito, embora com alguma moderação, mas há momentos em que devora, em pouco tempo, muita comida, um momento de crise, quando dificilmente consegue parar antes de a comida acabar ou de se sentir desconfortavelmente cheio.

Parece que o prazer está alijado, não é por causa do prazer que comem desse modo. O obeso mórbido come qualquer coisa, não importa muito qual é a comida. Relatam que, nesses momentos, não levam em conta se a comida está gostosa ou não, se é uma feijoada ou um feijão que sobrou tirado da geladeira, comido ali mesmo, em pé, no meio da madrugada ou no meio da tarde, sozinho, escondido da família, que lhe exige cumprir uma dieta. Esses são, portanto, momentos que mereceram especial atenção (Vilhena, Novaes \& Rocha, 2008).

\section{O laço mortífero, uma leitura possível}

Posto que todo filhote humano nasce, psíquica e biologicamente, prematuro, é pela via da alteridade que se formam o eu, nosso corpo como o vivenciamos e o sujeito do inconsciente. O que temos no início é um corpo fragmentado e desarticulado, o bebê antecipa uma unidade pela imagem que vê refletida: olha um corpo inteiro que primeiro pensa ser um outro, depois, pela confirmação da mãe, percebe ser o seu. $\mathrm{O}$ momento da formação do eu e do corpo como unidade, foram teorizados por Lacan (1998a) quando formulou o Estádio do Espelho (1949). É preciso ressaltar que, desde esse momento narcísico inicial, temos a presença do simbólico, já que é preciso a confirmação, a sustentação simbólica do Outro (encarnado nesse momento pela mãe ou quem cuida do bebê) para a imagem organizar-se. Lacan (1998a; 2005), aliás, não cessou de enfatizar isso. Respondendo a um ouvinte que lhe pedira uma articulação 
mais precisa entre o estádio do espelho e o significante, afirma: "Não creio que haja dois tempos no que ensinei algum dia" (Lacan, 2005, p. 39), o estádio do espelho e o imaginário em uma primeira etapa, e, posteriormente, o significante e o simbólico.

Seguindo essa observação, Mieli (2002, p. 13) ressalta que a criança espera do Outro "a medida do quanto a imagem especular... é efetivamente desejada por aquele para o qual ela se volta”. Portanto, não se trata apenas de uma confirmação de que aquela é a sua própria imagem, mas de uma apropriação dessa imagem conforme ela é aprovada, deseja por esse Outro tão importante. É preciso observar ainda que abordamos um processo instaurado a partir de um equívoco (penso primeiro tratar-se de um outro que me capturou, mas que sou eu mesmo), e que deixará consequências como tal. Daí Lacan (2005) observar que o outro especular instaura uma dialética. No entanto, desde já, ressaltamos que algo escapa desse reconhecimento, fica um resto do corpo que não se insere nesse processo especular e simbólico.

Essa imagem corporal é como um semblante tomado do campo do Outro para cobrir, vestir o corpo pulsional e fragmentado. Contudo, apesar de pertencer ao registro do imaginário (o registro da boa forma, que busca uma unidade, um fechamento) essa imagem não cairá tão bem, não deixamos de ter certo estranhamento com esse corpo. Se há uma instauração dessa imagem nos primeiros tempos, a acomodação acompanhará toda a vida do sujeito, "acompanhará as vicissitudes do real do corpo que, em perpétua transformação à revelia do próprio sujeito, estará à procura constante de uma imagem que confirme sua forma. A imagem de si tem a instabilidade como uma característica" (Mieli, 2002, p. 12). Essa imagem instável, devido ao próprio processo que resulta nela, é uma identificação que favorece sua oscilação entre sujeito e outro. $\mathrm{Na}$ obesidade mórbida, podemos situar essa instabilidade não apenas na considerável relação de ódio com o corpo como também na mudança gradativa do corpo, sua imagem e sua forma, a ponto de alguns pacientes, enquanto engordam, relatam o fato de reconhecerem-se cada vez menos no espelho.

A complexa relação do homem com seu corpo depende também do fato de que ele diz que tem um corpo, seu corpo, frisa Lacan (2006). Ele tem um corpo como tem um móvel, uma roupa, mas precisa dizer que tem, não passando assim fora do simbólico. Continuaremos a pensar a formação do eu e do corpo, mas juntamente com o advento do sujeito. Assim, o sujeito é aquele que não se sabe como sujeito que sustenta um discurso; ele não só não sabe o que diz, como não sabe quem o diz, ressalta Lacan (1992a). A causa desse sujeito se dá pelas operações de alienação e separação, e Lacan (1997, p. 
855) pontua com precisão que a alienação é própria do sujeito: "não é o fato de essa operação se iniciar no Outro que a faz qualificar de alienação". Alienação é quando o sujeito vai buscar no Outro um significante que o defina, dando-se conta, posteriormente, de que não há ali nada que o defina por completo. A alienação reside na divisão do sujeito: a causa do sujeito é o significante, ao passo que o Outro é o lugar da causa significante do sujeito, o campo dos significantes, explicando por que esse sujeito não pode ser causa de si mesmo.

Desse modo, o sujeito não surge em um significante, mas na cadeia significante, no ponto de intervalo entre, no mínimo, dois significantes. $S_{1}$ $\mathrm{S}_{2}$. Ou dito na forma clássica: "um significante representa um sujeito para outro significante" (1997, p. 854). Assim, o significante fica entregue às vicissitudes de um jogo pelo qual acabará significando coisas bem diversas, "esse caráter do significante marca de maneira essencial tudo o que é da ordem do inconsciente" (Lacan, 2002, p. 192-193). Essa operação liga singularmente sujeito e Outro (campo dos significantes), de modo tal que não há meio de definir-se um sujeito como consciente de si.

Laurent (1997a, p. 38) observa que, no momento de identificar-se com um significante que supostamente o definiria (o significante-mestre, $S_{1}$ ), o sujeito fica petrificado, "como se estivesse morto, ou como se lhe faltasse a parte viva de seu ser que contém seu gozo". O caso é que o sujeito, alienado pelo significante que vem do campo do Outro, identifica-se com este Outro, mas que sabemos incompleto. Essa falta fundamental na causa significante do sujeito, Lacan (1997) marca com uma barra, tanto no sujeito (expressando também sua dependência para com o Outro) como no Outro, no ponto em que este se caracteriza como falta. Assim, como bem aponta Soler (1997), o sujeito da alienação fica entre o petrificar-se num significante ou a indeterminação num deslizamento infinito entre os significantes da cadeia. Todavia, se a alienação é o destino, já que nenhum sujeito falante pode evitá-la, a separação pode ou não ocorrer, "a separação requer que o sujeito 'queira' separar-se... uma vontade de saber o que se é para além daquilo inscrito no Outro" (Soler, 1997, p. 62-63).

No caso dos obesos mórbidos, muitos deles foram obesos desde a infância, a maior parte das lembranças remotas já tem relação com o excesso, cada vez maior, de peso. Piadas no colégio, brigas com os colegas, observações dos parentes, dietas após dietas. Desde que lembram, são "gordinhos". Um rótulo que os define sem muito espaço para outra coisa, um signo que pode pesar, sem o sujeito conseguir deslizar por outras identificaçôes. 
Sentem-se, de fato, alienados e presos. Não se trata da alienação fundamental referente à falta que estrutura o sujeito, mas sim no oposto, algo que preenche completamente e, por isso mesmo, sufoca o sujeito.

É comum relatarem que, devido à obesidade, toda a vida está parada, não conseguem desempenhar outras funções, de mãe ou pai, marido ou esposa, filho, namorado, profissional. O problema da obesidade invade tudo o mais em suas vidas, e eles acreditam, assim, que, retirando a obesidade, a vida transcorrerá com a normalidade almejada. Desse modo, pedem à medicina por uma cirurgia que os separe desse signo sufocante, que lhes abram possibilidades de serem outras coisas que não só obeso mórbido. Pode ser um pedido legítimo, mas onde fica, nessa decisão, a vontade de saber o que se é para além daquilo inscrito no Outro? Esse movimento de separação não deve ser outorgado, mas efetuado pelo próprio sujeito.

É preciso acrescentar que o sujeito está entre significantes, não por acaso Lacan aponta que o desejo é veiculado justamente entre os significantes, no ponto intervalar da cadeia, ponto que se repete: "É sob a incidência em que o sujeito experimenta, nesse intervalo, uma Outra coisa a motivá-lo que não os efeitos de sentido com que um discurso o solicita, que ele se depara efetivamente com o desejo do Outro" (Lacan, 1997, p. 858), isso antes que possa chamá-lo de desejo ou mesmo imaginar seu objeto. Um desejo que se aloja na cadeia significante como desejo do Outro, e um sujeito que não encontra mais nenhuma forma de completude, constituído por uma falta radical.

O desejo tem íntima relação com a lei, ao desejar enveredo pelo caminho da lei, e é a função da lei que traça o caminho do desejo; "É na medida em que proíbe esse desejo que a lei impõe o desejá-la, pois, afinal, a mãe não é, em si mesma, o objeto mais desejável... Numa palavra, desejamos no mandamento" (Lacan, 2005, p. 120). Essa lei de que fala a psicanálise é simbólica, rege o homem conforme este é habitado pelo significante e que visa a regular seu acesso ao gozo. Na lei, o pai interdita o acesso à mãe, sob pena de castração, traçando o caminho do desejo.

Em um primeiro momento, a criança identifica-se com o objeto do desejo da mãe, o falo, ela é o falo da mãe, e é tomada como tal pela mãe; a criança busca satisfazer o desejo de sua mãe. É então que o pai intervém, inclusive como aquele que também priva a mãe do objeto de seu desejo, fazendo o falo desempenhar um papel importante e possibilitando o aparecimento da lei. Com a operação da castração o sujeito deve deslizar de uma dinâmica de ser ou não ser o falo de sua mãe, para a de ter ou não ter o falo nas trocas 
simbólicas que realizará doravante. Contudo, para entrar nesse nível das trocas, é preciso antes um momento em que não se tem; em outras palavras, ser castrado é decisivo para a assunção de ter o falo. Aqui, o pai, enquanto o que castra, tem que agir de modo eficaz, do lado da mãe bem como da criança. A castração, sublinha Lacan (2005), é uma operação simbólica realizada pelo significante Nome do pai, que é um operador estrutural, é o pai como agente de castração.

Na década de 1958, Lacan (1998b) toma o falo como um significante do desejo. O falo é um significante, articula ele, destinado a designar, em seu conjunto, os efeitos de significado, efeitos condicionados pela presença do significante. Um dos efeitos dessa presença é o de um desvio das necessidades do homem por ser ele falante. Quando põe a necessidade em palavras, algo não se articula, esse algo que fica de fora é o que se apresenta no homem como desejo, em todo seu caráter paradoxal, desviante, errático.

Em Freud (1996), podemos observar, no Édipo ou no Urvarter, que, com o pai assassinado, o que vemos é a impossibilidade do gozo como primária. Cai um véu exibindo uma proibição que é assentada sobre uma impossibilidade. Lacan (1997) sublinhou, no Seminário, sobre a ética que Édipo deita-se com a mãe, mas nem por isso alcança o objeto do desejo, que é falta radical. O mito é o enunciado de um impossível. Assim, a lei, que instaura a troca simbólica, é fundada no Outro, e o Nome do pai, significante da lei simbólica, é um "não!" ao gozo absoluto: a mãe não pode tomar o filho como objeto de seu gozo, como tampouco a este está permitido o gozo absoluto. Se "o papel da mãe é o desejo da mãe" (Lacan, 1992, p. 105), o papel do pai agente da castração, pai como significante, é separar, convocando novamente a mãe ao lugar de mulher causa de seu desejo (do pai). Desse modo, o pai possibilita que advenha no lugar do que seria apenas um objeto de gozo materno, um sujeito de desejo, constituído a partir de uma falta radical e fundadora.

O desejo está numa dimensão de equívoco, cativo dos significantes do Outro, é o desejo do Outro. Lacan (2005, p. 32) observa, no Seminário 10, que "o Outro se refere a meu desejo na medida do que lhe falta e de que ele não sabe", é nesse nível, da falta e do não saber, que o sujeito é implicado da maneira mais pregnante, "porque, para mim não há outro desvio para descobrir o que me falta como objeto de meu desejo" (Lacan, 2005, p. 32). Quando pedimos comida, por exemplo, trata-se também de uma demanda; quando justamente endereço com palavras o que é da ordem da pulsão e do desejo. A comida é algo que pode ser pedido, e nossa primeira comida é pedida aos berros, por isso ela entra como um objeto da demanda, adquirindo sinal de amor (Quinet, 2002). 
Entretanto, se para a necessidade há o alimento para a demanda aí implícita, por mais que a comida adquira sinal de amor, não há o que vá saciar, coma o quanto quiser, coma compulsivamente, mas não há objeto para a pulsão, o desejo é falta radical, constitutiva. É o que parece estar completamente eclipsado para o obeso mórbido, ele sabe e nos diz isso, que não come compulsivamente para saciar a fome, não é também pelo fato de a comida estar irresistivelmente apetitosa. Ele não percebe que a comida jamais saciará o desejo que anima sua demanda de mais um prato, é um desejo articulado a partir de sua falta, nenhum objeto satisfaz.

Assim, temos, por um lado, um falo como objeto do desejo, ao qual a criança, no início, identifica-se, mas também temos o pequeno $a$, o objeto causa do desejo. Se o desejo não é articulável, não se esgota na demanda, é falta radical, ele é articulado objetivamente com o objeto causa do desejo (Lacan, 2005, p. 138). Lembremos que, na fórmula fundamental, $S_{1}-S_{2}$ (Lacan, 1992), num primeiro momento, o $S_{1}$ é o significante interveniente, pois vem representar alguma coisa quando intervém numa bateria de outros significantes que já integram uma rede, representada por $S_{2}$. É o que dizíamos acerca da fórmula: o significante é o que representa um sujeito para outro significante. Seguramente $S_{1}$ é um ponto de marca, faz começar a engrenagem da cadeia de significantes, mas ainda há outras coisas que o sujeito faz entrar em virtude desse estatuto simbólico.

Desse modo, num segundo momento, uma vez intervindo nesse campo já constituído e tendo produzido o sujeito barrado pelo significante (\$), desse trajeto surge algo como uma perda. Sabemos que o Outro ao qual o sujeito identifica-se é incompleto, mas, nos anos 1960, Lacan (1997) diz que se trata de um Outro como lugar também do não sentido. Em 1973, comenta do seguinte modo a conhecida grafia do significante da falta no Outro, $S(\mathbb{A})$ : "Com essa grafia ajuntei uma dimensão a esse lugar do A, mostrando que, como lugar, ele não se aguenta, que ali há uma falha, um furo, uma perda. $\mathrm{O}$ objeto $a$ vem funcionar em relação a essa perda" (Lacan, 1985, p. 41), eis algo, arremata, completamente essencial à função da linguagem.

Esse é o Outro da separação, ao passo que o Outro da alienação é o tesouro dos significantes. Portanto, a separação diz do encontro com a falta do Outro, falta inerente ao desejo do Outro, e nela o sujeito tem de levar em conta que há um resto, o $a$, o "remanescente da operação fálica" (Laurent, 1997a, p. 40). Assim sendo, o sujeito define-se não só com referência ao significante como também por esse remanescente: temos um $\$$ cuja falta remete, por um lado, ao simbólico, à cadeia $S_{1}-S_{2}$, e, por outro, ao objeto $a$ e ao gozo. 
É possível ler as fórmulas de alienação e separação tendo o gozo como referência. Tomamos o sujeito como, fundamentalmente, um objeto do gozo do Outro, ressaltando que seu primeiro status é ser uma parte perdida desse Outro (que no início é geralmente a mãe). Primeiro vive no lugar do objeto $a$, do obscuro objeto do desejo materno, e só depois ingressa na cadeia de significantes como sujeito, \$. A esse respeito, Laurent (1997b) ressalta que, quando pensamos a identificação primária não só no nível do significantemestre, mas no do objeto que o sujeito definirá no final, delimitamos "a identificação completa: aquilo que ele foi, como tal, no desejo do Outro, não apenas no nível simbólico do desejo, mas como substância real envolvida no gozo. Ele só pode tentar recuperá-lo ou identificá-lo dentro do desenvolvimento da cadeia de significantes" (Laurent, 1997b, p. 44).

A noção de gozo que aqui nos orienta é, sobretudo, a desenvolvida por Lacan (1992) no Seminário 17, um gozo em relação íntima, "primitiva”, para usar a palavra escolhida, com o campo do significante. Por um lado, temos um gozo que é caminho para a morte, ultrapassa os limites impostos pelo "princípio de prazer" e atenta contra a vida. Esse gozo aponta que a barreira entre o princípio do prazer e seu mais além é bem mais fluida, uma relação delicada que Freud (1996) analisa no "Mais além do princípio de prazer". O gozo absoluto é a morte, no entanto, aquém deste há gozos parciais e possíveis.

Temos um bônus de gozo que cai no campo simbólico, nos diz Lacan, e a ele acedemos por um desvio possibilitado pela função da linguagem, a cadeia significante como meio de um gozo possível ao falante, "o significante, então, se articula por representar um sujeito junto a outro significante. É daí que partimos para dar sentido a essa repetição inaugural, na medida em que ela é repetição que visa ao gozo" (Lacan, 1992, p. 45).

Assim, tanto o \$ quanto o advento de um gozo possível, ambos são resultados importantes da operação fundamental significante, possibilitandonos estabelecer não uma equivalência, pois não se trata de ter o mesmo valor ou pertencer ao mesmo registro, mas uma relação, uma conexão entre a falta constitutiva do sujeito barrado e o gozo que lhe é possível somente a partir da operação significante fundamental. Parece ser um modo de entender o que nos diz Lacan (1992) ao sublinhar que "somos seres nascidos do mais de gozar, resultado do emprego da linguagem" (Lacan, 1992, p. 62).

Laurent (1997a) situa dois modos de definir a falta do sujeito. A primeira, representada por $S_{1}$, é quando o sujeito é definido pelo significante-mestre e uma parte fica de fora dessa definição. Ocorre que "sempre que isolamos uma 
das identificações do sujeito, precisamos em seguida encontrar a fantasia $(\$ \triangleright a)$ que a acompanha, a fantasia que lhe traz algum gozo" (1997a, p. 38). Desse modo, a segunda definição da falta, representada por $a$, é uma tentativa de inscrever o gozo no simbólico, "o sujeito tenta inscrever uma representação do gozo no interior do Outro no texto de sua fantasia, e tenta definir a si mesmo através dessa fantasia $(\$ \diamond a)$. Ao tentar definir-se dessa maneira, ele cria outra falta: o fato de que seu gozo é somente parcial" (1997a, p. 38).

Assim, continua o autor, a própria alienação (entendida como o fato do sujeito, posto que não tem identidade, ter de identificar-se a algo) negligencia ou encobre o fato de que, "em um sentido mais profundo, o sujeito se define não apenas na cadeia significante, mas, no nível das pulsões, em termos de seu gozo em relação ao Outro" (1997b, p. 43). É por essa via que Laurent entende, e o acompanhamos quando Lacan diz que a interpretação não visa tanto ao sentido, mas a reduzir os significantes a seu não senso, só assim reencontramos os determinantes da conduta do sujeito (Lacan, 1998).

Acompanhando nossas colocações, devemos pensar a obesidade mórbida não só a partir da falta significante e do desejo como também da falta representada por $a$ e do gozo parcial. O gozo é uma dimensão visível na obesidade mórbida, a sensação desse comer com sofreguidão não é o prazer, o degustar prazeroso, quando muito é um estranho prazer, trata-se de um gozo. A comida estaria, nesse caso, mais como um objeto de gozo a ser devorado. Lembra-nos o pequeno bebê, quando não passa de um objeto do gozo materno, e que bem poderia ser devorado com sofreguidão caso ali não se dê uma separação, a operação de castração.

Esse sujeito passa a vida funcionando de acordo com os pontos de condensação de seu gozo, o que lhe dá, como vimos, algo como uma identidade, daí a dificuldade de abrir mão desses modos de gozar. Esses pontos enigmáticos de condensação retornam continuamente na compulsão que os caracteriza. Uma vez na busca do gozo pulsional, "não se sabe onde isso vai dar. Começa com as cócegas e termina com a labareda de gasolina" (Lacan, 1992, p. 68).

Freud, no polêmico texto de 1920, Mais além do princípio de prazer, perguntando pela existência de um funcionamento mais primitivo e elementar do que o princípio do prazer, investigou o fenômeno da compulsão à repetição, a partir principalmente dos sonhos das neuroses traumáticas. Com a observação dessa "perpétua recorrência da mesma coisa", ele supôs que "na vida anímica existe realmente uma compulsão à repetição que se instaura além do princípio de prazer" (Freud, 2006, p. 22). Esse texto é uma 
virada na teorização de Freud, quando tenta entender fenômenos clínicos ligados a essa repetição e aprimora a noção de pulsão de morte. Com esse texto, podemos dizer que se tem acesso à pulsão, na experiência, pela repetição, e que, nessa compulsão à repetição, retornam os pontos enigmáticos do sujeito que apontam um determinado gozo. Assim, Lacan (1997) observa que, na obra freudiana, "a repetição de uma necessidade só funciona como ocasião para a necessidade de repetição" (Lacan, 1997, p. 272), esse é o "x" da questão. Em outras palavras, ocasião para a compulsão à repetição justamente por dizer do movimento que é próprio da pulsão e repetição como veículo de gozo que desponta nesse mais além.

A repetição é a característica última da cadeia de significantes, é o essencial que determina com o que se lida no inconsciente. Contudo não deixa de ser um paradoxo a cadeia com sua repetição veicular algo que é, em última instância, seu próprio limite, a saber, o gozo. É possível observar que Lacan (1997), sem perder de vista os resultados de sua investigação acerca do gozo impossível, sádico, do Seminário 7 (1997), fala de um gozo que se articula de modo íntimo com o campo do significante, um gozo que não passa pela transgressão, mas de um bônus que cai no campo significante.

\section{Um buraco sem fundo, a via do gozo}

Em seus relatos, os obesos mórbidos frequentemente falam de um buraco que tentam preencher, um vazio que não sabem definir muito bem, e que só conseguem parar de comer quando se sentem completamente cheios, o que, por sua vez, só é alcançado quando estão, após momentos de comilança compulsiva, desconfortavelmente cheios. Um buraco que só se enche para, em seguida, apresentar-se novamente, compulsivamente, exigindo mais. Eles parecem nos falar dessa falta radical e constitutiva do sujeito, a que nada preenche. Uma falta que não deixa de se relacionar, como vimos, com os modos de gozo do sujeito.

$\mathrm{Na}$ via do gozo, pensando no laço dessas pessoas com a comida, como apontamos, esta parece estar mais como objeto condensador de gozo do que como objeto do desejo. Não se trata de uma fome que nunca passa, nem um desejo de comer que nunca se satisfaz, o desejo é insatisfeito por natureza. A relação com a comida é determinada por essa outra via. Fatso (1980), simpático personagem de um filme homônimo, vive às voltas com sua gula e sua obesidade quando a morte de um primo obeso atravessa sua vida. A família exige que emagreça para não ter o mesmo destino.

Um dia, ao voltar do trabalho, como de hábito, vai abocanhar um hot dog quando percebe que uma mulher o está olhando, olhar de sedução, de desejo. 
Então ele hesita com o sanduíche suspenso no ar, um tempo de não comer, de ao menos abrir a possibilidade: o desejo ou o gozo? (Amorim \& Sant'ana, 1999). No caso de Fatso, ele consegue um acordo, nem só o desejo nem só o gozo, casa-se e continua a comer fartamente. Na vida real, em geral, paira uma forte dúvida sobre a veracidade do amor e do desejo os quais vêm do outro, sejam os pais, amigos, namorado. Como abrir esse momento de possibilidade, de dúvida? Os obesos sentem-se cada vez mais colados a esse laço mortífero com a comida, engolidos nesse gozo voraz.

Assim, temos que nos perguntar não só por essa relação sufocante com a comida, as limitaçôes sociais e sofrimentos relatados frequentemente, enfim, pela identificação com tudo que é, para eles e seus familiares, ser obeso mórbido e pela fantasia que acompanha isso, mas também nos perguntamos pelo gozo que vem junto. Gozo pelo qual, como vimos, o sujeito também busca identificar-se tentando inscrevê-lo no campo do Outro. O gozo é uma dimensão evidente na obesidade e na compulsão que a caracteriza, a obesidade mórbida é um modo particular de gozar, o obeso goza e o faz principalmente de um só modo, caracterizado pelo comer compulsivo que o distingue.

A imagem do corpo na obesidade traz consequências e sofrimento, afetando a relação do sujeito com seu corpo e com o outro, mas não fiquemos só no aparente, é o corpo pulsional, corpo atravessado pelo gozo, que ocupa, primariamente, toda a cena. Quando estão em um episódio de comilança, comendo compulsivamente, parece que todo aquele enorme corpo a engordar, a cuidar, fica em suspenso, como se não existisse. Eles comem sem parar e só se dão conta do quanto comeram depois. O obeso, antes de tudo, não é um corpo obeso, é um devorar compulsivo, insatisfeito e voraz. Como se a obesidade mórbida se ancorasse num ponto específico de condensação de gozo que captura momentaneamente o sujeito. Sendo assim, como conciliar a exigência social contemporânea de beleza (leia-se: magreza), ou mesmo a vontade própria de serem magros, com o particular de seu gozo?

Perguntamo-nos: afinal, na obesidade mórbida, quem devora quem? Pode a comida encarnar um outro devorado, mas também devorador? Pois o sujeito parece ser, aos poucos, devorado nesse laço mortífero, consumindo, aos poucos, suas forças, sua mobilidade, seu desejo, sua vida. Essas pessoas nos relatam uma verdadeira batalha (diária) contra sua compulsão; batalha perdida. Assim, o corpo gordo a ser operado, cuja imagem refletida denuncia um descontrole, só toma a cena em um segundo tempo, o que está lá primariamente é um certo modo de relacionar-se com a comida, um certo modo de gozo.

O sujeito, em seus primórdios, está na posição de objeto, como suporte do desejo do Outro e, posteriormente, operando com sua própria falha originária 
e a partir do resto (a) que fica dessa operação, ele sai dessa posição de objeto e se torna um sujeito de desejo a ter objetos. Se parere, sublinha Lacan (1998), é gerar a si mesmo, jogar sua partida sozinho, proporcionar o que lhe diz respeito. Já assinalamos que o pedido à medicina de curarse da obesidade é também um pedido de separar-se de uma identificação sufocante com o "ser obeso", como também de separar-se de um modo de gozo voraz. Talvez pedido de poder gozar de outros modos, mais articulados ao simbólico. Nesse tempo do se parere, o que se desenha é a própria assunção do Nome do Pai, possibilitando ao sujeito ser gerido pela lei simbólica.

O obeso mórbido é também a própria imagem do descontrole, desregramento, falta de medida, desgoverno com relação a uma norma, uma lei. Fischler, do ponto de vista da Sociologia, em um interessante estudo, analisa a imagem que se constrói do obeso bonzinho e bonachão versus o obeso maligno (o capitalista explorador, o comerciante de escravos, entre outras figuras). Sublinha justamente que essas imagens relacionamse à ideia de que o grande obeso burlou uma lei, na partilha dos bens (sobretudo o mais precioso deles, a comida), tomou uma parte que não lhe era de direito, deixando o outro em falta. Essa suspeita pesa sobre os gordos, que devem realizar uma "restituição simbólica", aceitando os papéis que lhes são reservados (Fischler, 1995, p. 71).

Guardadas as diferenças, trata-se de uma pesquisa sociológica e antropológica, podemos nos perguntar o que há por trás dessas imagens sociais. É interessante que tenha aparecido justo a questão da falta; no caso da pesquisa citada, uma falta encarnada na comida e outros bens, mas que aqui entendemos como a falta estrutural do sujeito. Também aparece o "a mais" que o obeso usufrui, para nós se trata de um gozo a mais. Desse modo, isso não deixa de causar conflitos no encontro com o outro, pois o obeso remeteria o outro a uma falta, mesmo que encarnada na comida, além de mostrar o usufruto de um gozo que o outro, a princípio, não acessaria. Como se o obeso dissesse: "você está em falta e ainda curto um gozo a mais que você".

O Outro de quem o sujeito tem que se separar sob ameaça de castração é também, desde o início, um Outro enigmático, ameaçador em seu apetite voraz, em seu gozo. Daí haver certo alívio para a criança, que temia ser engolida por esse Outro, quando se encontrava na posição de obscuro objeto do desejo de sua mãe. $\mathrm{Na}$ verdade, além do desejo, um objeto com toda a sua carga de gozo, uma vez encarregado de realizar a fantasia materna. Já começamos a apontar que a ideia de um Outro devorador nos 
remete à leitura da relação do obeso mórbido com a comida: é ele devorador ou devorado? Comilão ou comido? Poderíamos dizer que algo da relação primitiva do sujeito com esse Outro devorador, uma relação nos termos do gozo, retorna na relação estabelecida com a comida.

Quando Lacan (1997) se debruça sobre Sade, nos diz que o gozo é sempre sentido pelo corpo. Acrescenta ainda que a imagem tem um oco, o que se vê na imagem, para além de sua captura, é um vazio. Pouco tempo depois, Lacan (2005) retoma o assunto, de modo a nos ser útil, e desenvolve que a imagem caracteriza-se por uma falta, o objeto causa de desejo convocado nela não pode aparecer, é impossível aparecer. $\mathrm{Na}$ imagem, o desejo está velado e relacionado com uma ausência, e por isso ela tem função de captação para o desejo. O neurótico, arremata ele, recua diante de confirmar um Outro como, essencialmente, Outro barrado, em falta, mas que, no nível da imagem, a castração já está posta a cada encontro com o outro, ela se coloca a cada fratura que se produz à aproximação da imagem do semelhante.

No caso do obeso mórbido, o encontro com o outro semelhante parece evidenciar essa fratura. $\mathrm{Na}$ imagem disforme do obeso parece que só vemos uma grande distância desse outro, parece só haver espaço para a dessemelhança, para o estranhamento, o afastamento e o isolamento. O que o obeso apresenta é uma imagem que não é desejada pelo outro, que causa repulsa. Vimos, a partir de Mieli (2002), o quão importante é que essa imagem seja acolhida, desejada, aprovada pelas pessoas importantes para o sujeito, mesmo que se trate de um processo contínuo e com ajustes constantes. Muito do sofrimento relatado por eles diz respeito a como são vistos, como são tratados: as pessoas olham curiosas, fazem piadas, comentam entre si, com uma espécie de receio. Perguntam-se como eles deixaram a coisa chegar a esse ponto; por que não fizeram algo a tempo? O obeso mórbido, não raro, é alvo de repulsa e agressividade, como se sua imagem realmente ofendesse, invadisse o outro, ameaçasse.

Quanto aos obesos, não é incomum que se percebam tão diferentes, e mesmo desfigurados, justo quando se miram no olhar do outro, um familiar ou alguém na rua. Que imagem se trata na obesidade mórbida? Como vimos, a imagem de si é, por natureza, instável e serve para vestir, mais ou menos bem, o corpo pulsional, acompanhando as vicissitudes desse corpo. Ela também é uma construção que oscila entre o sujeito e o outro. Na obesidade mórbida, a relação do sujeito com o outro está bastante prejudicada e limitada, e as "vicissitudes" são mais do que o sujeito dá conta, pois o corpo pulsional toma a cena. O percurso, relatam, é que se reconhecem cada vez menos no espelho enquanto engordam e mudam, a imagem refletida vai ficando estranha, como se não fossem eles mesmos. 


\section{Conclusão}

A obesidade mórbida é paradigmática numa sociedade cuja característica é um consumo ilimitado e um hedonismo desenfreado (Rocha, 2007). O homem contemporâneo, esvaziado, obedece à ordem de sua época: Goze! No tempo do performático, a combinação de um foco na iniciativa pessoal, de uma liberação inédita dos costumes e de uma pulverização das referências, levou à produção de uma individualidade que age por ela mesma. Diante desse cenário, dessa performance exigida, encontramos um indivíduo marcado pela insuficiência, e uma das formas de padecer é a compulsão.

A tecnologia permite fazer muitas manipulações, mas esse poder não liberta. Nesse movimento, podemos observar que o homem busca um modo de constituir-se, de fabricar referências, comumente intervindo no próprio corpo. Para Ortega (2003), nessas práticas, residiria o processo de fragmentação de um ideal unitário. Ou seja, a valorização de partes da anatomia que surge como um reflexo de um fenômeno mais amplo que se atualiza em diversas aspectos da vida contemporânea e que diz respeito à noção de que o sujeito pode e deve ser engenheiro de si mesmo, montando, remontando, recriando suas formas e, por fim, redesenhando as fronteiras deste corpo de forma infinita, a ponto de negar sua materialidade numa espécie de "rejeição corporal da corporeidade", ou ainda no que Sibília (2003) nomeou de aversão à carne.

Nossa sociedade de performances encoraja essas práticas de modificação, de modo a criar um problema no cerne da estruturação do sujeito, da subjetivação mesmo (Ehrenberg, 1998). Assim, se a contemporaneidade é marcada pelo excesso, um gozo hoje e agora, a obesidade mórbida encaixa-se muito bem nessa série: comer com prazer agora e sem limites. Por outro lado, é paradigmática, também, numa cultura da performance e da ação, obcecada por fabricar autonomia; o obeso mórbido tem pouco controle ao comer compulsivamente e perde, gradativamente, sua autonomia e mobilidade (Rocha, 2007). A produção de um sujeito autônomo e, simultaneamente, responsável pela sua aparência, como sinalizou Ehrenberg (1998), forja um determinado tipo de subjetividade que gera um mal-estar definido pela sensação de estar-se aquém dos ideais. A obesidade traz, ainda, o inverso oposto do culto ao corpo, da valorização estética (Vilhena, Novaes \& Medeiros, 2006).

A obesidade mórbida parece estar mais próxima de uma forma de escravidão, quando a liberdade vacila no seio do sujeito, uma vez que se encontra submetido às exigências contemporâneas, por um lado, e ao seu modo de gozar por outro lado, que lhe desfigura a imagem e o paralisa aos poucos. $\mathrm{O}$ obeso não deixa restos, come até a última migalha, mas continua 
insatisfeito, voraz, saco sem fundo. Mas quem come quem? O obeso parece aniquilar-se aos poucos, devorado pela comida. Outro modo de gozar deve ser buscado. É preciso que se dê uma separação do sujeito com essa comida como objeto condensador de gozo, que se constitua outra relação com a comida. É o efeito que se quer da cirurgia bariátrica? Que faça um corte nesse laço com a comida? Algumas vezes, parece ser esse o efeito que se dá nos obesos que operam e lidam bem com todas as implicaçôes e restrições que a "nova vida" acarreta.

É preciso desfazer esse nó de gozo, esse modo de gozar inflexível, exigente, que caracteriza a obesidade mórbida. Nela temos uma atividade do erotismo oral, gozo oral, mas o comer compulsivo também está do lado da pulsão de morte, refere-se ao horror de um gozo por ele mesmo ignorado. A comida também apontaria para uma tentativa de quantificação, pois se está sempre contando e somando as calorias, pesando as gramas da dieta, os quilos a mais ou a menos, a porção a mais ou a menos. A comida permitiria um ciframento do gozo, portanto tentativa de algum governo dele (Rocha, 2007).

Mas os pacientes fiam-se na medicina para resolver, ou mesmo decifrar, sua obesidade, buscando apenas soluções fora deles. Pode haver aí uma cilada. $\mathrm{Na}$ cirurgia bariátrica, diminui-se o estômago, quase como se tirasse um pedaço fora; o que significa essa busca por tirar um pedaço do corpo? Fabricar ali, no bisturi, uma falta? Um corte com valor de separação? Em geral os pacientes relatam que a vida mudou depois da cirurgia. O corte da cirurgia parece apontar para uma verdadeira passagem: a vida "antes" e a vida "depois".

A cirurgia pode ter uma indicação necessária, mas os médicos, postos no lugar de mestres, só podem atuar naquilo que aparece. Não possibilitam acesso ao que há de subjetivo, de desejo e de gozo no laço com a comida, enfim, ao que há do sujeito na construção da obesidade mórbida bem como no movimento rumo à cada vez mais comum cirurgia bariátrica (Rocha, 2007). Frequentemente o que observamos é o total descolamento do sujeito com o seu sintoma. O corpo tratado apenas como organismo; corpo da ordem da natureza, do qual a medicina se ocupa com tanta competência (Vilhena \& Novaes, no prelo). Há um silêncio imposto aos órgãos em sua significação mais profunda, como se estivéssemos diante de um corpo sem narrativa. Em outras palavras, "o enfermo como subjetividade foi sendo progressivamente excluído e silenciado da cena da enfermidade... excluído que era de qualquer implicação no processo de adoecimento" (Birman, 2003, p.10).

Concluímos, então, indagando se, além do desejo ancestral de escapar aos limites do corpo natural, as proezas da ciência e das novas tecnologias não 
levam o sujeito contemporâneo a crer que tal tarefa é possível. Não existiria também, tão forte quanto o sonho de fabricar um novo corpo, a busca de realização de um outro desejo?

\section{Referências}

Amorim, L. \& Sant'Ana, M. M. (1999). A compulsão de comer. Ágora: Estudos em Teoria Psicanalítica, 1 (2), 21-29.

Birman, J. (2003). Mal-estar na atualidade: a psicanálise e as novas formas de subjetivação. Rio de Janeiro. Civilização Brasileira.

Ehrenberg, A. (1998). La fatigue d'être soi: dépression et société. Paris: Odile Jacob.

Fatso (1980). Direção Anne Bancroft. Produção: Anne Bancroft. Intérpretes: Anne Bancroft; Don DeLuise; Ron Carey e outros. Roteiro: Anne Bancroft. EUA: 20th Century Fox. 1 videodisco (93 min): NTSC: son., color.

Fischler, C. (1995). Obeso benigno obeso maligno. In: D. B. Sant'Anna, D. B. de. (org.). Políticas do corpo. (p. 69-80). São Paulo: Estação Liberdade.

Freud, S. (1996). Totem e tabu. In: S. Freud. Edição standard brasileira das obras psicológicas completas de Sigmund Freud (v. 13, p. 13-163). Rio de Janeiro: Imago. (Texto original publicado em 1914).

Freud, S. (2006). Más allá del principio de placer. In: S. Freud. Obras completas: más allá del principio del placer, psicología de las masas y análisis del yo y otras obras (v. 18, p. 3-62). Buenos Aires: Amorrortu. (Texto original publicado em 1920).

Lacan, J. (2002). O seminário, livro 3: as psicoses. Rio de Janeiro: Jorge Zahar. (Texto original publicado em 1956).

Lacan, J. (1997). O seminário, livro 7: a ética da psicanálise. Rio de Janeiro: Jorge Zahar. (Texto original publicado em 1960).

Lacan, J. (2005). O seminário, livro 10: a angústia. Rio de Janeiro: Jorge Zahar. (Texto original publicado em 1963).

Lacan, J. (1992). O seminário, livro 17: o avesso da psicanálise. Rio de Janeiro: Jorge Zahar. (Texto original publicado em 1970). 
Lacan, J. (1992). O seminário, livro 20: mais, ainda. Rio de Janeiro: Jorge Zahar. (Texto original publicado em 1973).

Lacan, J. (2006). El seminário 23: el sinthoma. Buenos Aires: Paidós. (Texto original publicado em 1976).

Lacan, J. (1998). O estádio do espelho como formador da função do eu tal como nos é revelada na experiência psicanalítica. In: J. Lacan. Escritos. (p. 96103). Rio de Janeiro: Jorge Zahar. (Texto original publicado em 1949).

Lacan, J. (1998). A significação do falo. In: J. Lacan. Escritos. (p. 692-703). Rio de Janeiro: Jorge Zahar. (Texto original publicado em 1958).

Laurent, E. (1997a). Alienação e separação I. In: R. Feldstein, B. Fink \& M. Jaanus (org.). Para ler o Seminário 11 de Lacan. (p. 31-41). Rio de Janeiro: Jorge Zahar.

Laurent, E. (1997b). Alienação e separação II. In: R. Feldstein; B. Fink \& M. Jaanus (org.). Para ler o Seminário 11 de Lacan. (p. 42-51). Rio de Janeiro: Jorge Zahar.

Mieli, P. (2002). Sobre as manipulaçôes irreversiveis do corpo. Rio de Janeiro: Contra Capa.

Novaes, J. V. (2007). Sobre a tirania da beleza. Revista Polêmica [on-line]. (18), Disponível em: <http://www.polemica.uerj.br/pol18/oficinas/lipis_4. htm>. (Acesso em: 10 jan. 2008).

Novaes, J. (2006). O intolerável peso da feiurra: sobre as mulheres e seus corpos. Rio de Janeiro: Garamond.

Novaes, J. V. (2003). Da cena do corpo ao corpo em cena. Estética feminina e cirurgia plástica. In: K. Castilho \& D. Galvão. (org.). A moda do corpo: o corpo da moda. (p. 15-158). São Paulo: Esfera.

Ortega, F. (2003). Práticas de ascese corporal e constituição de bioidentidades. Cadernos Saúde Coletiva, 11(1), 59-77.

Quinet, A. (2002). As 4+1 condiçôes da análise. Rio de Janeiro: Jorge Zahar.

Rocha, L. J. L. (2007). De grão em grão a galinha nunca enche o papo: algumas reflexões acerca da obesidade mórbida. Revista Polêmica [on-line]. (22), Disponível em: <http://www. polemica.uerj.br/pol22/oficinas/lipis_4.htm>. (Acesso em: 4 fev. 2008). 
Sibília, P. (2003). O homem pós-orgânico: corpo, subjetividade e tecnologias digitais. Rio de Janeiro: Relume Dumará.

Soler, C. (1997). O sujeito e o Outro II. In: R. Feldstein, B. Fink \& M. Jaanus (org.). Para ler o Seminário 11 de Lacan. (p. 58-67). Rio de Janeiro: Jorge Zahar.

Vilhena, J., Novaes, J. V. \& Rocha, L. J. L. (2008). Comendo, comendo e não se satisfazendo: apenas uma questão cirúrgica? Obesidade mórbida e o culto ao corpo na sociedade contemporânea. Revista Mal-Estar e Subjetividade [online]. 2 (8). Disponível em: <http://www.unifor.br/notitia/file/2165.pdf>. (Acesso em: 2 set. 2008).

Vilhena, J., Novaes, J. V. \& Medeiros, S. (2006). A violência da imagem: estética, o feminino e a contemporaneidade. Revista Mal-Estar e Subjetividade, 1 (5), 111-146.

Vilhena, J. \& Novaes, J. (prelo). O corpo e suas narrativas: culto ao corpo e envelhecimento feminino. Revista Psychologica, (50). 